\title{
Fibrothecoma of Ovary with Virilizing Features
}

\author{
${ }^{1}$ Subha S Sengodan, ${ }^{2}$ Mohana D Velappan, ${ }^{3}$ Aiswarya R Putty, ${ }^{4}$ Kapikulam P Mohanasundari
}

\section{ABSTRACT}

Introduction: Fibrothecoma is a rare tumor of the ovary accounting for about 3 to $4 \%$ of all ovarian tumors. They are usually unilateral and have a good prognosis compared with other tumors of the ovary.

Case report: Here we report a rare case of fibrothecoma with virilizing features in a postmenopausal woman who presented with complaints of abdominal mass with virilizing symptoms, such as excess terminal hair growth and clitoromegaly.

Conclusion: Surgery is the treatment of choice for fibrothecoma, and it has a good prognosis. Virilizing features are usually not common in fibrothecoma. Here we present a rare case of fibrothecoma with virilizing features.

Keywords: Fibrothecoma, Rare presentation, Virilization.

How to cite this article: Sengodan SS, Velappan MD, Putty AR, Mohanasundari KP. Fibrothecoma of Ovary with Virilizing Features. J South Asian Feder Menopause Soc 2018;6(1):69-71.

Source of support: Nil

Conflict of interest: None

Date of received: 10 January 2018

Date of acceptance: 27 January 2018

Date of publication: August 2018

\section{INTRODUCTION}

Fibrothecoma ${ }^{1}$ is an uncommon ovarian tumor of gonadal stromal cell origin. It accounts for 3 to $4 \%$ of all ovarian tumors. ${ }^{2}$ They are derived from the celomic epithelium or the mesenchymal cells of the gonads. They are mostly unilateral and present in all age groups. They are diagnosed earlier than the epithelial cell tumors, surgery is the management for most and have a good prognosis. Sex cord stromal tumors are a rare cause of hyperandrogenism, ${ }^{3}$ and here we present a case of postmenopausal woman who presented with mass in abdomen with hyperandrogenic features, which was diagnosed as fibrothecoma. ${ }^{1}$

\footnotetext{
${ }^{1,2}$ Associate Professor, ${ }^{3}$ Junior Resident, ${ }^{4}$ Assistant Professor

${ }^{1-4}$ Department of Obstetrics and Gynecology, Government Mohan Kumaramangalam Medical College \& Hospital, Salem Tamil Nadu, India

Corresponding Author: Subha S Sengodan, Associate Professor, Department of Obstetrics and Gynecology Government Mohan Kumaramangalam Medical College \& Hospital, Salem, Tamil Nadu, India, Phone: +919444039077 e-mail: drppsamysubha@gmail.com
}

\section{CASE REPORT}

A 60-year-old postmenopausal woman, P6L4, presented with complaints of abdominal distension and lower abdominal pain for 6 months. She also had slowly progressive increase in terminal hair growth over the face, arms, and legs for the past 3 years. She had regular cycles previously, married, and had six children all by normal vaginal delivery, last child birth was 30 years back, no history of any contraceptive use. She experienced mild scalp hair loss, but no acne, voice change or galactorrhea, symptoms of increased intracranial tension, or loss of weight or appetite. She was a known hypertensive on treatment with no history of diabetes or thyroid.

On physical examination, she had terminal coarse hair growth of male pattern over the face, arms, legs, and abdomen with temporal balding. Her Ferriman Gallwey score for hirsutism was 15. Systemic examination was normal. On per abdomen examination, there was a mass of about $15 \times 15 \mathrm{~cm}$, nontender, extending from the pelvis up to the epigastrium, firm in consistency with restricted mobility. Examination of her genitalia revealed clitoromegaly.

Her vitals were stable and her blood investigations revealed hemoglobin $11.5 \mathrm{gm} \%$, blood sugars within normal limits. Ultrasonography of abdomen and pelvis revealed a huge pelvoabdominal mass with solid and cystic components. Contrast-enhanced computed tomography of abdomen was done which showed a $22 \times 19 \mathrm{~cm}$ abdominopelvic cystic mass with septations. Hormonal assay showed an elevated cancer antigen 125 of 52.4 $\mathrm{U} / \mathrm{mL}$, but other markers, such as serum testosterone, thyroid function tests, inhibin, adrenocorticotropic hormone, dehydroepiandrosterone sulfate were normal. On staging laparotomy, a huge cystic mass of $15 \times 15 \mathrm{~cm}$, found arising from the right ovary, was removed, which on cut section revealed septations and hemorrhagic fluid. The mass was removed and total abdominal hysterectomy with bilateral salpingo-oophorectomy was done (Figs 1 and 2).

Histological examination of sections from the ovary showed neoplasms composed of fascicles of plump spindle-shaped cells and moderate amount of cytoplasm with oval nuclei and focal areas showing clear cells. Foci of calcifications were seen. Extensive areas of hemorrhage and necrosis were also seen. The features were suggestive of fibrothecoma (Figs 3 and 4). 


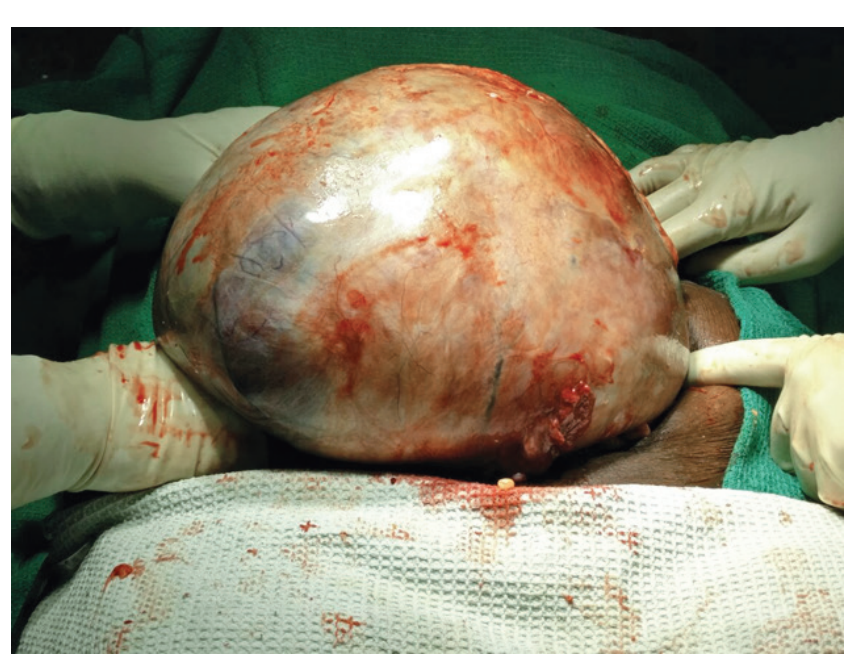

Fig. 1: Gross picture of the ovarian mass

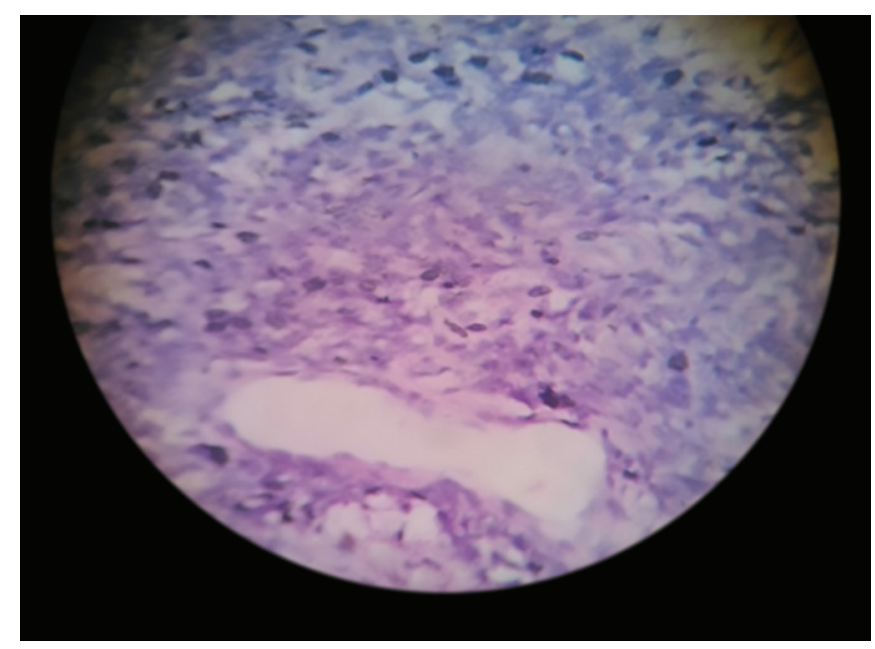

Fig. 3: Histopathological examination—high-power view

\section{DISCUSSION}

Virilizing tumors of the ovary constitute about $<0.2 \%$ of cases of hyperandrogenism ${ }^{3}$ and $<1 \%$ of all ovarian tumors. ${ }^{4}$ The histological classification of ovarian tumors by the World Health Organization (WHO) is based on the cells of origin whether from celomic surface epithelial cells, germ cells, and mesenchyme. ${ }^{5}$

Ovarian fibrothecomas ${ }^{1}$ are uncommon tumors of gonadal stromal cell origin accounting for about 3 to $4 \%$ of all ovarian tumors. ${ }^{2}$ They belong to the sex cord stromal tumors classification of ovarian neoplasms which includes Sertoli-Leydig cell tumors, granulosa cells, fibroblasts, and theca cells. Ovarian tumors that present with hyperandrogenism include Leydig cell tumors, Sertoli cell tumors, steroid cell tumors not otherwise specified, and ovarian thecomas. ${ }^{6}$ Tumors from granulosa and theca cells are often estrogenic, and Sertoli-Leydig cells are usually hyperandrogenic. However, it may be vice versa. The newer WHO classification includes a

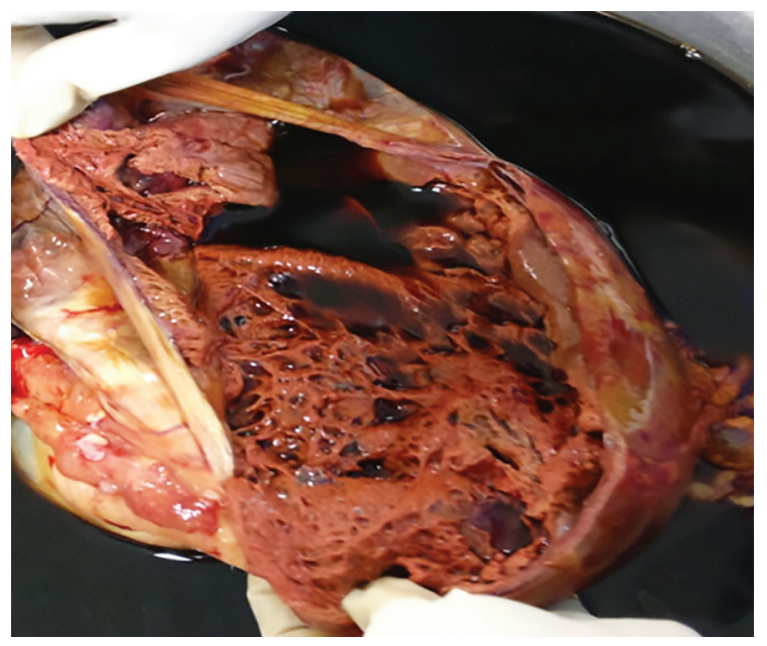

Fig. 2: Cut section of the ovarian mass

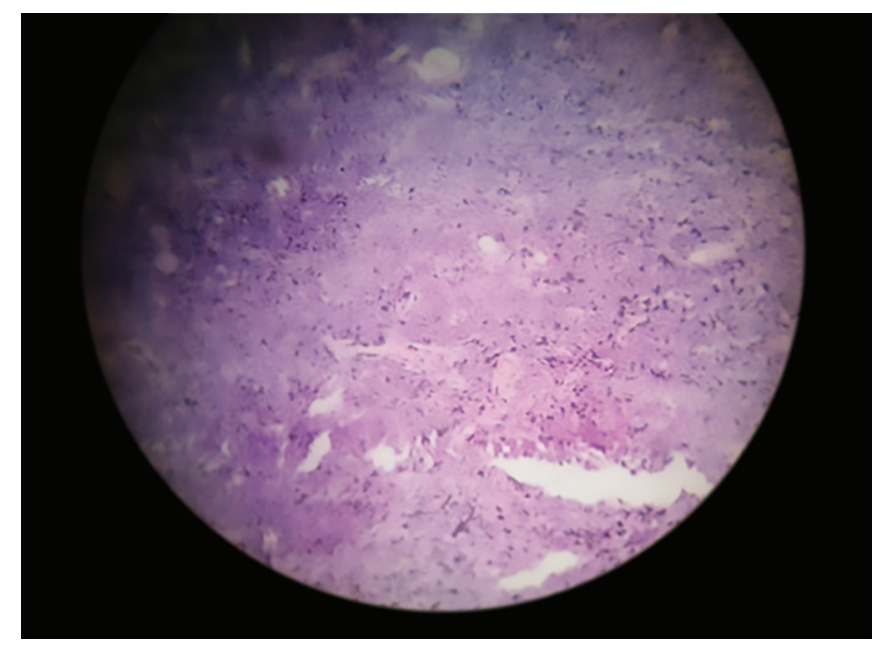

Fig. 4: Histopathological examination-low-power view

separate entity as "pure stromal tumors" instead of the fibroma-thecoma group. Fibrothecomas generally occur in postmenopausal age group, are rarely malignant, and are unilateral in $95 \%$. Histologically, they are composed of spindle, oval, and round cells forming various amounts of collagen and also theca cells that contain lipids. Endocrine manifestations are rare. In a case series of 24 cases of fibrothecoma, no endocrine manifestation was noted. ${ }^{7}$ Here we present a rare case of ovarian fibrothecoma with endocrine manifestations. They are mostly benign and surgery is the definitive management with good prognosis.

\section{REFERENCES}

1. Scully, RE.; Young, RH.; Clement, PB. Tumours of the ovary, maldevelopedgonads, fallopian tube and broad ligament. Washington (DC): AFIP; 1996. pp. 189-201.

2. Prat J; FIGO Committee on Gynecologic Oncology. Staging classification for cancer of the ovary, fallopian tube and peritoneum. Int J Gynecol Obstet 2014 Jan;124(1):1-5. 
3. Carmina E, Rosato F, Janni A, Rizzo M, Longo RA. Extensive clinical experience: relative prevalence of different androgen excess disorders in 950 women referred because of clinical hyperandrogenism. J Clin Endocrinol Metab 2006 Jan; 91(1):2-6.

4. Koonings PP, Campbell K, Mishell DR Jr, Grimes DA. Relative frequency of primary ovarian neoplasms: a 10-year review. Obstet Gynecol 1989 Dec;74(6):921-926.
5. Scully, R.; Sobin, L. Histological typing of ovarian tumours. Vol. 9. New York: Springer Berlin; 1999.

6. Morgan LS. Hormonally active gynaecologic tumours. Semin Surg Oncol 1990;6(2):83-90.

7. Chechia A, Attia L, Temime RB, Makhlouf T, Koubaa A. Incidence, clinical analysis, and management of ovarian fibromas and fibrothecomas. Am J Obstet Gynecol 2008 Nov;199(5):473. e1-473.e4. 